\title{
In-Vivo Degradation of DNA-Based Therapeutic BC 007 in Humans
}

\author{
Hanna Davideit ${ }^{1}$ - Susanne Becker ${ }^{2}$. Johannes Müller ${ }^{3} \cdot$ Niels-Peter Becker $^{4} \cdot$ Peter Göttel $^{3}$. Ayşe Abay ${ }^{2}$. \\ Angela Sinn ${ }^{5} \cdot$ Matthias Grossmann $^{5} \cdot$ Markus Mallek $^{6} \cdot$ Annekathrin Haberland $^{1}$ (D) Hardy Weisshoff ${ }^{7}$
}

Published online: 23 January 2019

(c) The Author(s) 2019

\begin{abstract}
Background and Objectives Since there is no clear evidence in the literature to show how non-modified single-stranded DNA (ssDNA) drugs are metabolized in humans, we assessed the metabolism of BC 007, an ssDNA therapeutic, under development as a neutralizer of autoantibodies against G-protein-coupled receptors. In-vitro, investigating its stability in monkey plasma and serum, a successive 3 '-exonuclease degradation resulting in several $n-x$ degradation products has been previously reported. Here, we investigated the metabolism of BC 007 in humans after intravenous application to autoantibody-positive healthy subjects, in line with Phase I safety testing.

Methods ${ }^{1} \mathrm{H}$-NMR was applied for $n-x$ degradation product search and beta-aminoisobutyric acid (bAIBA) measurement in urine; ultra-performance liquid chromatography-mass spectrometry was also used for the latter. Colorimetric assays were used for quantification of uric acid in serum and urine.

Results Fast degradation prohibited the detection of the intermediate $n-x$ degradation products in urine using ${ }^{1} \mathrm{H}-\mathrm{NMR}$. Instead, NMR revealed a further downstream degradation product, bAIBA, which was also detected in serum shortly after initial application. The purine degradation product, uric acid, confirmed this finding of fast metabolism.

Conclusion Fast and full degradation of BC 007, shown by nucleic bases degradation products, is one of the first reports about the fate of a ssDNA product in humans.
\end{abstract}

Annekathrin Haberland

haberland@berlincures.de

1 Berlin Cures GmbH, Robert-Rössle-Str. 10, Laboratory, 13125 Berlin, Germany

2 Department of Clinical Affairs, Berlin Cures GmbH, Knesebeckstr. 59-61, 10719 Berlin, Germany

3 Management, Berlin Cures GmbH, Knesebeckstr. 59-61, 10719 Berlin, Germany

4 Department of Regulatory Affairs, Berlin Cures GmbH, Knesebeckstr. 59-61, 10719 Berlin, Germany

5 PAREXEL-PAREXEL International GmbH, Early Phase Clinical Unit, Klinikum Westend, Spandauer Damm 130, 14050 Berlin, Germany

6 Department of Toxicology and Drug-Monitoring, Medizinisches Versorgungszentrum Dr. Eberhard \& Partner Dortmund, Brauhausstr. 4, 44137 Dortmund, Germany

7 Department of Chemistry, NMR Facility, Humboldt University of Berlin, Brook-Taylor-Straße 2, 12489 Berlin, Germany

\section{Key Points}

This is the first investigation to show the very fast degradation of a thymidine- and guanosine-containing oligonucleotide drug, BC 007, in humans, down to the nucleic bases semi-final and final degradation products, beta-aminoisobutyric acid (bAIBA) and uric acid.

The estimation of bAIBA in urine is a valuable parameter to follow the metabolism and excretion of BC 007 , particularly since the less broken-down exonuclease products of BC 007 could not have been detected in urine. 


\section{Introduction}

The oligonucleotide sequence of BC 007 (formerly GS-522) was originally selected as a potential short-lasting thrombin inhibitor with a rapid onset of action for transient anticoagulation during coronary bypass graft surgery; however, it failed because of the lack of a persistent effect resulting in a sub-optimal dosing profile.

However, as the substance can neutralize pathogenic autoantibodies [1], it is now back to the center of interest and clinical evaluation. Therefore, metabolization of the substance in humans has again become an urgent issue.

Connected with the original development, Shaw et al. (1995) investigated the degradation of BC 007 in monkey serum and plasma under in vitro conditions [2]. These authors developed an anion-exchange HPLC method for the detection of the full-length sequence and its 3 '-degradation products.

BC 007, a single-stranded DNA (ssDNA) 15-mer consisting of nine guanosine (purine nucleoside) and six thymidine (pyrimidine nucleoside) nucleosides of the following sequence 5'-GGTTGGTGTGGTTGG-3', was successively degraded in their in vitro experiments, also showing in addition to the main peak of full length sequence, $n-1$ to $\mathrm{n}-6$ in decreasing amounts when incubated for $2 \mathrm{~h}$ in monkey plasma at $37{ }^{\circ} \mathrm{C}$ [2]. However, since the "half-lives observed for GS-522 (BC 007) in various plasmas are (were) all greater than the observed in vivo elimination half-life reported in monkeys" the authors assumed "that in vivo plasma metabolism plays a minor role in the overall in vivo elimination" anyway [2].

With this limited information in mind, a NMR method was developed that could simultaneously detect both the full-length sequence and n-1 to n-4 while giving different NMR signals when binding onto the complementary sequence of $\mathrm{BC}$ 007. This method was applied to investigate the urine of subjects who received $\mathrm{BC} 007$, in line with Phase I safety and tolerability testing.

Additionally, semi-final and final degradation products of the pyrimidine and purine metabolism, beta-aminoisobutyric acid (bAIBA) and uric acid, respectively, were measured. The results, which enable clarification of $\mathrm{BC} 007$ metabolism, are described here.

\section{Materials and Methods}

\subsection{Materials}

Samples were obtained from participants of the Phase I trial testing the safety and tolerability of BC 007 (NCT02955420), EudraCT-no. 2015-005236-18.
In a randomized, double-blind, placebo-controlled single ascending dose study, 3 cohorts (each consisting of 8 male healthy subjects aged $18-45$ years) were dosed once with 15 , 50 , and $150 \mathrm{mg}$ of BC 007 intravenously (i.v.) (over $20 \mathrm{~min}$ ). An additional 8 elderly healthy subjects of both sexes (55-70 years) received $150 \mathrm{mg} \mathrm{BC007}$ or placebo. Afterwards, in an open-labeled study, 7 cohorts of 6 elderly volunteers each with evidence for autoantibodies against G-protein-coupled receptors (55-75 years) were tested with a single dose of $50,150,300,450,750,1350$, and $1900 \mathrm{mg}$ BC 007. Infusion duration increased from $20 \mathrm{~min}(50$ and $150 \mathrm{mg}$ ) over $40 \mathrm{~min}(300,450$, and $750 \mathrm{mg})$ and $75 \mathrm{~min}(1350 \mathrm{mg})$ up to $105 \mathrm{~min}(1900 \mathrm{mg})$. Lower doses were partially applied with a combination of bolus and infusion, while the higher doses (1350 and $1900 \mathrm{mg}$ ) were applied as infusion only.

Each participant signed an informed consent form.

Subject safety was carefully monitored (electrocardiogram, blood pressure, clinical chemistry safety parameters, injection site reactions, physical examination, adverse events). Blood samples were taken from before the infusion began until $24 \mathrm{~h}$ after for clinical chemistry, coagulation, hematological and pharmacokinetic analysis. Urine was collected for analysis.

\subsection{NMR Sample Preparation for BC 007 Full Length Detection and Search for n-1 to n-4 Degradation Products in Urine Samples}

Six 50-mL urine samples from subjects in the Phase 1 study were concentrated to volumes of $<1 \mathrm{~mL}$ using Microsep Advance Centrifugal Devices (MWCO $10 \mathrm{~K}$; Pall Corporation, MI, USA). All centrifugations were performed on a Hettich laboratory centrifuge (EBA20; Hettich Lab Technology, Tuttlingen, Germany) using an eight-place fixed angle rotor at room temperature. In preliminary experiments, it was found that BC 007 and the degradation products $\mathrm{n}-1$ to $n-4$, although they are below the cutoff limit, do not pass through the filter material. The filters were washed three times with distilled water, were concentrated to a volume of $<1 \mathrm{~mL}$, and the resulting supernatants were transferred into an Eppendorf tube containing $228 \mathrm{nmol}$ complementary sequence of $\mathrm{BC} 007$. One hundred $\mu \mathrm{L}$ of deuterium oxide $\left(\mathrm{D}_{2} \mathrm{O}\right)$ was added to the solution and diluted to $1 \mathrm{~mL}$ with distilled $\mathrm{H}_{2} \mathrm{O}$. The ${ }^{1} \mathrm{H}-\mathrm{NMR}$ spectra were recorded analogously according to the method described below.

\section{3 bAIBA Detection in Urine and Plasma}

\subsubsection{NMR for Detection of bAIBA in Urine Samples}

A $600 \mathrm{MHz}$ Bruker spectrometer (Bruker Biospin, Rheinstetten, Germany) was used for one-dimensional (1D) proton ${ }^{1} \mathrm{H}-\mathrm{NMR}$ data acquisition of urine samples. 1D spectra 
were acquired using excitation sculpting (Bruker Topspin 3.0 pulse sequence library 'zgesgp', [3]) for suppression of water resonance with a relaxation delay of $8 \mathrm{~s}$ and a $30^{\circ}$ flip angle to guarantee near complete longitudinal relaxation at a reasonable measuring time, and with a spectral width of $24 \mathrm{ppm}$ and 512 transients. Data processing included phase correction, which was performed manually for each spectrum, and baseline correction over the entire spectral range. The baseline was additionally corrected over the integrated regions of the methyl signal of bAIBA. All spectra were aligned and normalized to 3-(trimethylsilyl)-propionic acid$\mathrm{d}_{4}$-sodium salt (TSP) reference signal. NMR resonances of the methyl signal of bAIBA were quantified using the peak deconvolution tool of Topspin 3.0. Manual peak picking and deconvolution were performed to delineate the signal integrations and calculate the bAIBA concentration based on the standard TSP signal. The methyl doublet of bAIBA at $1.2 \mathrm{ppm}$ was apparently superimposed by two weak signals. The proportion of these signals in the total intensity of the bAIBA doublet was subtracted after deconvolution. The trimethyl group of TSP was not overlapped by signals from urine components.

Although the NMR method does not require calibration curves for signal quantification, a calibration curve was prepared from bAIBA-spiked urine samples of an untreated person. With this calibration curve, the processed and normalized bAIBA signals of the real samples were quantified in addition to quantification against TSP. Both methods resulted in good agreement.

\subsubsection{Ultra-Performance Liquid Chromatography-Tandem Mass Spectrometry (UPLC-MS/MS) for Detection of bAIBA in Urine and Plasma Samples}

bAIBA in urine and plasma using UPLC-MS/MS was measured by Medizinisches Versorgungszentrum Dr. Eberhard \& Partner Dortmund (Dortmund, Germany). Briefly, prior to analysis, all plasma and urine samples, calibration standards and quality control samples were thawed and allowed to equilibrate at room temperature. Then, $50 \mu \mathrm{l}$ of each were transferred into Eppendorf reaction vials. Internal standard $(200 \mu \mathrm{l})$ (cell-free amino acid mixture- ${ }^{13} \mathrm{C},{ }^{15} \mathrm{~N}$; Sigma Aldrich, Germany; $500 \mu \mathrm{l}$ in $200 \mathrm{ml}$ methanol) was added to each vial which was then vortexed for $15 \mathrm{~s}$. After a short incubation period at room temperature for $15 \mathrm{~min}$, all vials were repeatedly vortexed for $15 \mathrm{~s}$ and centrifuged at 16,000 RCF for $5 \mathrm{~min}$. For derivatization, $10 \mu \mathrm{l}$ of supernatant was transferred into Eppendorf reaction vials and mixed with $70 \mu \mathrm{l}$ of borate buffer and $20 \mu \mathrm{l}$ derivatization reagent 6-aminoquinolyl-N-hydroxysuccinimidyl carbamate in acetonitrile (included in AccQ-Tag ${ }^{\text {TM }}$ Ultra Derivatization Kit, Waters, Germany). All vials were incubated for $10 \mathrm{~min}$ at room temperature. Subsequently, all samples were again mixed with $70 \mu \mathrm{l}$ borate buffer and transferred to sample cups. Chromatographic separation of the three isobars, alpha-, beta- and gamma-aminobutyric acid, was carried out on an ACQUITY UPLC ${ }^{\circledR}$ system with HSS T3 column $(1.8 \mu \mathrm{m}$; $2.1 \mathrm{~mm} \times 100 \mathrm{~mm}$, Waters, Germany) using $0.1 \%$ formic acid in ULC water and $0.1 \%$ formic acid in acetonitrile as mobile phase. Quantification was performed using a Micromass Quattro Premier-XE (Waters, Germany) in ES + mode. MassLynx ${ }^{\mathrm{TM}}$ NT version 4.1 (Waters, Germany) was used to control all parameters of LC and MS/ MS and for quantification.

Validation of the quantitative mass spectrometry includes sensitivity, linearity, precision, stability, matrix effects and accuracy. For sensitivity testing, five levels of bAIBA were analyzed for calculating the calibration curve $\left(r^{2}\right)$. Each sample was prepared twice. Concentrations were at 5/4/3/2/1/0 $\mu \mathrm{M}$. For limit of detection (LOD) the signalto-noise ratio should be $>3$. Limit of quantification is the lowest concentration of analyte that can be quantified. The coefficient of variation (CV) should be $<20 \%$, and the accuracy has to be within $\pm 20 \%$. The signal-to-noise ratio is defined as $>5$.

For calculating calibration linearity $\left(r^{2}\right)$, seven calibration levels were measured. Each calibration level was prepared twice. The calibration data were plotted on a calibration graph. Concentrations were on $\mathrm{x}$-axis and signals were on y-axis. The correlation coefficient $\left(r^{2}\right)$ should be at least 0.997 .

To estimate the intra-assay precision, 10 samples of two concentrations each $(8.8 \mu \mathrm{M}$ and $88 \mu \mathrm{M})$ were measured. Additionally, the day by day CV was determined; a CV under $10 \%$ was accepted.

Stability was tested over a range of 10 days. Samples were stored under three conditions, ambient temperature, $2-8{ }^{\circ} \mathrm{C}$ and frozen $<-20{ }^{\circ} \mathrm{C}$. The accepted deviation was $<10 \%$.

To exclude matrix effects, three samples were measured natively. Subsequently samples were diluted with physiological sodium chloride solution $(w=0.9 \%)$. The recovery rate was calculated as follows:

Recovery rate $=\frac{\text { Result undiluted sample } \cdot \text { Dilution factor }}{\text { Result diluted sample }}$

The laboratory participates twice a year in a ring trial, including 32 amino acids and biogenic amines. Unfortunately, bAIBA is not included. For this reason, we performed a comparative measurement with another laboratory.

The percentage of measured bAIBA (sum of bAIBA over the whole urine collection period of $24 \mathrm{~h}$ after application) compared to the maximal possible to find amount of bAIBA was computed from the mass spectrometry 
data as follows: $1 \mathrm{~mol} \mathrm{BC} 007$ results in 6 mol thymine nucleotides after complete cleavage. By now including the molecular weights of BC 007 of approximately $4800 \mathrm{~g} / \mathrm{mol}$ and bAIBA of $103.12 \mathrm{~g} / \mathrm{mol}$ and the applied amount of $\mathrm{BC}$ 007/subject in grams, the maximal detectable amount of bAIBA can be calculated as $0.058,0.097,0.174$, and $0.245 \mathrm{~g}$ bAIBA at the applied doses of $0.45,0.75,1.35$ and $1.9 \mathrm{~g} \mathrm{BC} 007$, respectively, if $100 \%$ of the applied BC 007 is metabolized to bAIBA. Then, the amount of bAIBA found (i.e., the sum of all collecting intervals minus the corresponding pre-dose values) was set in relation to the maximal detectable amount of bAIBA and was expressed as $[\%]$.

\subsection{Uric Acid Detection in Urine and Serum}

\subsubsection{Uric Acid in Urine Samples}

Uric acid in the urine samples was measured in duplicate using the test kit Fluitest ${ }^{\circledR}$ UA (Uric Acid 5+1) from Analyticon ${ }^{\circledR}$ Biotechnologies AG (Lichtenfels, Germany) which was adapted for analysis on a 96-well plate. It is a kinetic colorimetric assay, based on uricase-mediated decomposition of uric acid to allantoin, carbon dioxide, and hydrogen peroxide. The latter forms a quinone diimine dye in the presence of 4-aminoantipyrine, DHBSA, and peroxidase, which is measurable at $546 \mathrm{~nm}$. The shift in color is directly proportional to the uric acid concentration. A urine control set from Analyticon ${ }^{\circledR}$ Biotechnologies AG (Lichtenfels, Germany) with two different uric acid levels (level 1: 413-703 $\mu \mathrm{mol} / \mathrm{L}$ and level 2: 722-1229 $\mu \mathrm{mol} / \mathrm{L}$ ) was used as quality control during measurement to ensure the validity of each assay. The assay reportable range was between 11.9 and $1487 \mu \mathrm{mol} / \mathrm{L}$. Samples with uric acid concentrations $>$ $1487 \mu \mathrm{mol} / \mathrm{L}$ were diluted 1 to 2 and 1 to 4 in distilled water (Water HPLC gradient grade, Carl Roth $\mathrm{GmbH}$ ).

Since the measurements were run from previously frozen samples, the influence of freezing/thawing on the recovery of uric acid in control urine (Analyticon ${ }^{\circledR}$ Biotechnologies AG) was tested previously, excluding major disturbances. Five freeze/thaw cycles were tested at two concentration levels (control level 1: 413-703 $\mu \mathrm{mol} / \mathrm{L}$ and control level 2: $722-1229 \mu \mathrm{mol} / \mathrm{L}$ ) with recovery of $98 \%$ after the 5 th freeze/ thaw cycle compared to the fresh urine control sample.

\subsubsection{Uric acid in Serum Samples}

Uric acid in serum was measured by Synlab Pharma Institute (a division of Synlab Umweltinstitut $\mathrm{GmbH}$ ), on behalf of PAREXEL International $\mathrm{GmbH}$, Berlin, Germany, using a colorimetric assay (Beckman Coulter assay OSR6 series) of the following principle: "Uric acid is converted by uricase to allantoin and hydrogen peroxide. The formed hydrogen peroxide reacts with $\mathrm{N}, \mathrm{N}$-bis(4-sulfobutyl)-3,5-dimethylaniline, disodium salt (MADB) and 4-aminophenazone in the presence of peroxidase to produce a chromophore, which is read biochromatically at $660 / 800 \mathrm{~nm}$. The amount of dye formed is proportional to the uric acid concentration in the sample". The reference range was $208.3-428.4 \mu \mathrm{mol} / \mathrm{L}$ for male subjects and 154.7-357.0 $\mu \mathrm{mol} / \mathrm{L}$ for female subjects.

Uric acid was measured in serum samples collected during the treatment period at $0 \mathrm{~min}$ (pre-dose), $20 \mathrm{~min}, 4 \mathrm{~h}$, and $24 \mathrm{~h}$ after bolus and infusion or infusion only of $450 \mathrm{mg}$ (application duration $40 \mathrm{~min}$ ) and $750 \mathrm{mg}$ (application duration $40 \mathrm{~min}$ ) $\mathrm{BC} 007$ or $0 \mathrm{~min}, 50 \mathrm{~min}, 80 \mathrm{~min}, 4 \mathrm{~h}$, and $24 \mathrm{~h}$ after infusion of $1350 \mathrm{mg}$ BC 007 given over $75 \mathrm{~min}$. After the infusion of $1900 \mathrm{mg}$ BC 007 over $105 \mathrm{~min}$, uric acid was measured in serum samples during the treatment period at $0 \mathrm{~min}$ (pre-dose), $50 \mathrm{~min}, 110 \mathrm{~min}, 4 \mathrm{~h}$ and $24 \mathrm{~h}$.

\subsection{Statistics}

For statistical evaluation, a 1-sided paired Students $t$ test was applied (Excel Office 365). Statistical significance was given and indicated as $\alpha=0.05-0.01\left(^{*}\right), \alpha=0.01-0.001$ $(* *), \alpha \leq 0.001(* * *)$.

\section{Results}

\subsection{NMR for Detection of Full-Length BC 007 and Degradation Products in Urine Samples}

A $600 \mathrm{MHz}$ NMR method for the simultaneous detection of full length BC 007 and successive degradation products

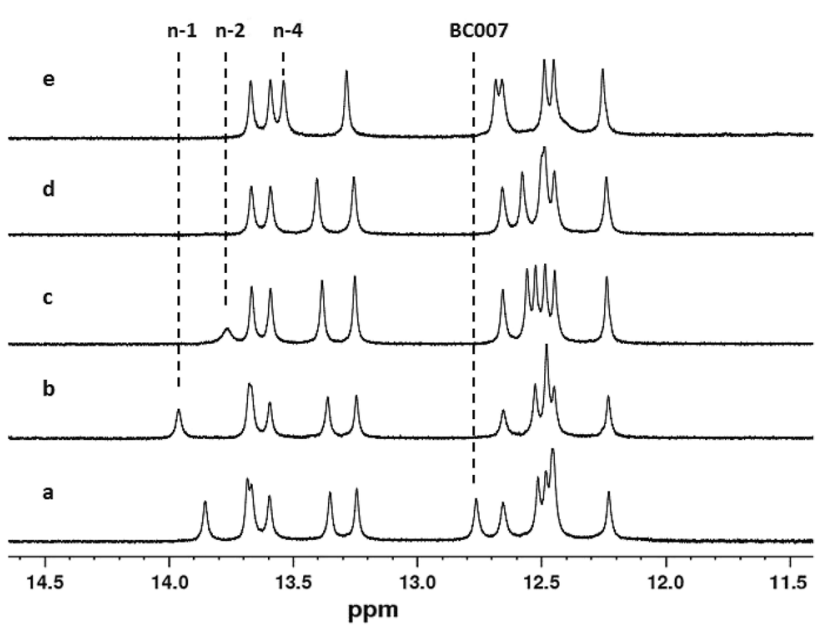

Fig. 1 Nuclear magnetic resonance (NMR) spectra of hybridization products of complementary BC 007 with BC 007 full length (a) and n-1 to n-4 degradation products (b-e) at 288 Kelvin, all spiked in human urine 
up to $\mathrm{n}-4$ was developed, using a $\mathrm{BC} 007$ complementary sequence (5'-CCAACCACACCAACC-3') which was able to bind and hybridize full length and n-1, n-2, n-3, and n-4 simultaneously, resulting in different specific NMR spectra able to discriminate single different hybridization products when spiked in urine (Fig. 1).

Further degradation products $(n-5, n-6 \ldots)$ led to nonuniform hybridization products, resulting in strong line broadening of the corresponding NMR signals, making an evaluation impossible.

As shown in Fig. 1, spectra of the four double strands between $\mathrm{BC} 007$ to $\mathrm{BC} 007 \mathrm{n}-4$ and the complementary sequence of $\mathrm{BC} 007$, allow the identification of five possible degradation products.

It can also be seen from Fig. 1 that the first and the last pair of the double strand do not form stable H-bonds and, for this reason, no NMR signals can be observed for these imino protons. For the double strand of BC 007 with its complementary sequence, this yields six thymine imino protons and seven guanine imino protons in the spectrum. Analogously, for the double strand of BC 007n-4 and the BC 007 complementary sequence, 4T and 5G imino signals are observed.

However, the LOD with $4 \mu \mathrm{M}$ was relatively high (spiked urine samples). When testing urine samples from subjects who received infusions of $750 \mathrm{mg}$ or $1350 \mathrm{mg} \mathrm{BC} 007$ over $40 \mathrm{~min}$ or $75 \mathrm{~min}$, full length BC 007 was barely detectable using this method and, surprisingly, no degradation products $(n-x)$ were observed.

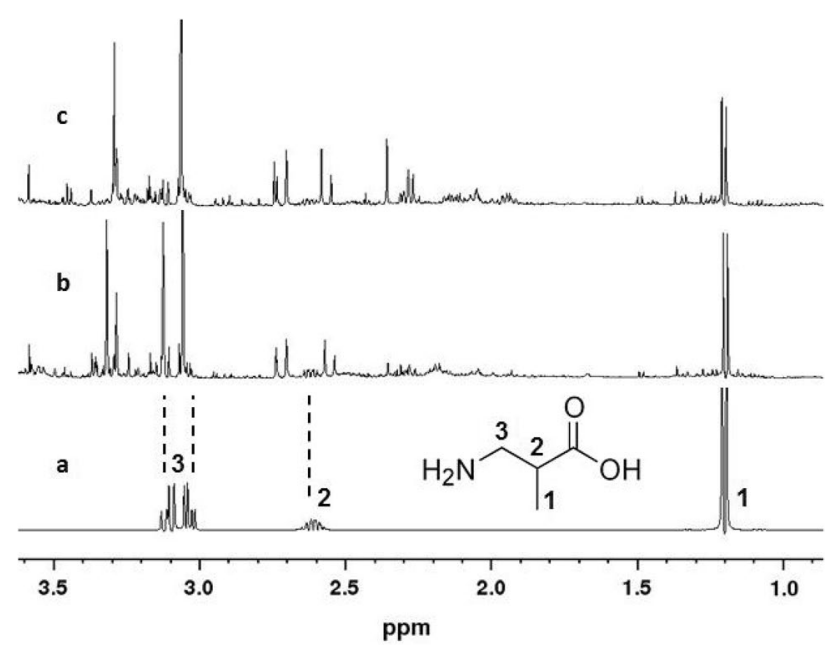

Fig. 2 Nuclear magnetic resonance (NMR) spectra of beta-amino butyric acid (bAIBA) in deuterium oxide $\left(\mathrm{D}_{2} \mathrm{O}\right)(\mathbf{a})$, a urine sample spiked with $10 \mathrm{mg}$ bAIBA/50 $\mathrm{mL}$ urine (b), and a real urine sample from the clinical study (c)

\section{2 bAIBA Determination in Urine Samples Using NMR}

Looking at the NMR spectra for further breakdown products, only catalytic metabolites of the pyrimidines (thymidine), ending in bAIBA and its further breakdown products such as methylmalonic acid semialdehyde, would theoretically be detectable using this NMR technology (Fig. 2). It should be noted, however, that methylmalonic acid semialdehyde represents an unstable substance, which is, therefore, not commercially available for comparison purposes. Because of its instability, no conclusions about its formation can be drawn from the obtained spectra.

In the urine samples collected at $0-2,2-4,4-8,8-12$, and 12-24 h after infusion of $1350 \mathrm{mg} \mathrm{BC} 007$ over $75 \mathrm{~min}$, bAIBA was measured (Fig. 3) and quantified against the internal standard TSP (Fig. 4a). There are particularly striking differences in bAIBA content at the different sampling intervals, the highest being 2-4 $\mathrm{h}$ after the end of application.

The further downstream metabolite, methylmalonic acid semialdehyde, was not detected (Fig. 3).

\section{3 bAIBA Determination in Urine Samples Using UPLC-MS/MS}

For verification of the NMR findings of the urine bAIBA concentration, a routine UPLC-MS/MS method was used (Fig. 4b), showing only small deviations from the NMR data

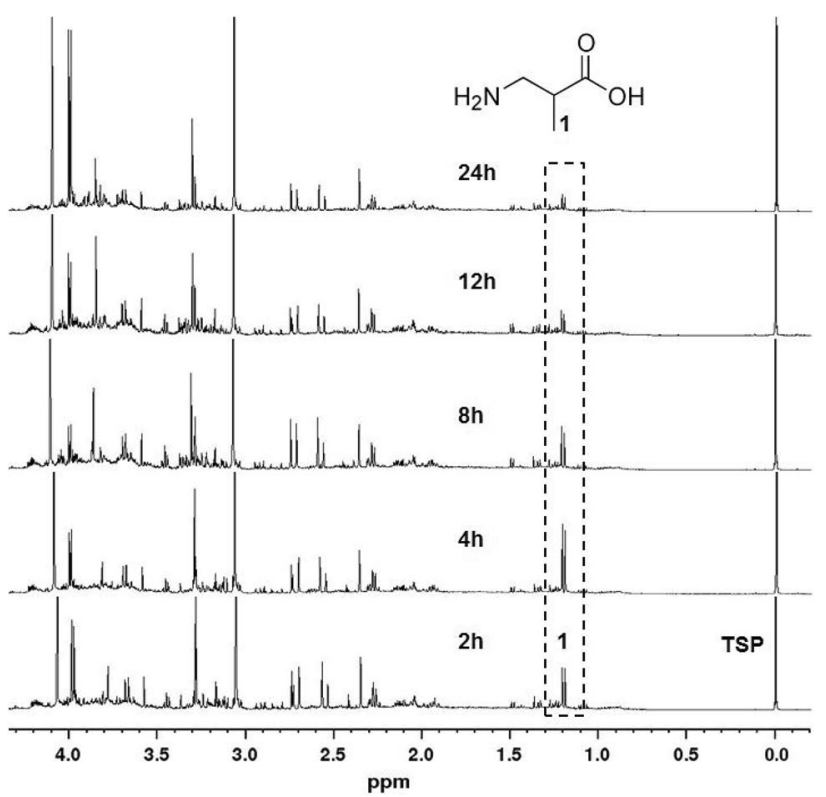

Fig. 3 Nuclear magnetic resonance (NMR) spectra of urine samples collected at 0-2 h (2 h), 2-4 h (4 h), 4-8 h (8 h), 8-12 h (12 h), and 12-24 h (24 h) after infusion of $1350 \mathrm{mg} \mathrm{BC} \mathrm{007.} \mathrm{3-(Trimethylsilyl)-}$ propionic acid- $\mathrm{d}_{4}$-sodium salt (TSP) served as internal standard 


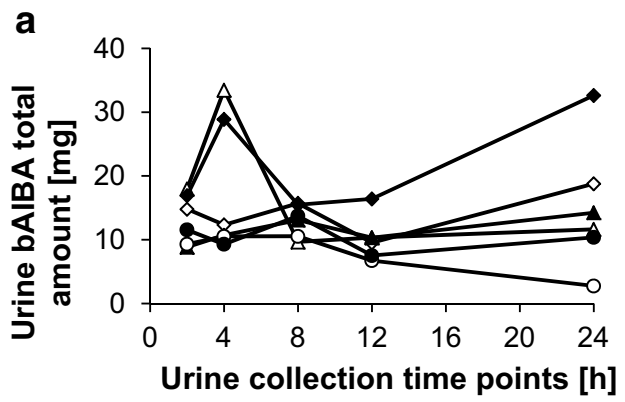

Fig. 4 Total beta-aminoisobutyric acid (bAIBA) amount in urine samples in (mg) of single subjects (triangle-1, diamond-2, filled triangle-3, filled diamond-4, circle-5, filled circle-6) collected at $0-2 \mathrm{~h}$, 2-4 h, 4-8 h, 8-12 h, and 12-24 h (respective dot at corresponding time axis) after infusion of $1350 \mathrm{mg} \mathrm{BC} 007$ (over $75 \mathrm{~min}$, infusion only) measured via nuclear magnetic resonance (NMR) (a) or ultra-

\section{a}

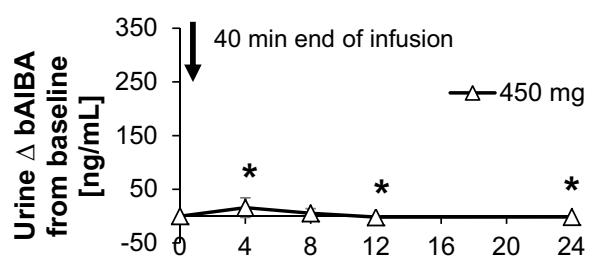

Sampling timepoint [h]

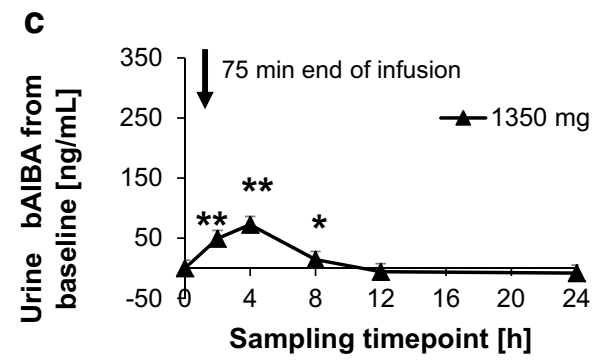

Fig. 5 Difference in beta-aminoisobutyric acid (bAIBA) urine concentration from the baseline value $[\mathrm{ng} / \mathrm{mL}]$ measured via ultraperformance liquid chromatography-tandem mass spectrometry (UPLC-MS/MS). Samples were collected at different time intervals as indicated in the figure. Dosing was $450 \mathrm{mg}$ (over $40 \mathrm{~min}$, bolus and infusion or infusion only) (a), $750 \mathrm{mg}$ (over $40 \mathrm{~min}$, bolus and

(Fig. 4a). This is a way of confirming results of the even non-validated NMR method. Applying this routine UPLCMS/MS method, the bAIBA concentration of the different dosing cohorts (450, 750, 1350 and $1900 \mathrm{mg}$ ) was tested as depicted in Fig. 5. Here, the differences to the baseline (predose) levels are shown. It became obvious that with all dosing cohorts, the maximum of the urine bAIBA concentration was reached at the sampling interval of $0-4$ or $2-4 \mathrm{~h}$, when taken at 1350 and $1900 \mathrm{mg} \mathrm{BC} 007$ cohorts, which declined to pre-dose levels around 8-12 $\mathrm{h}$ after application.

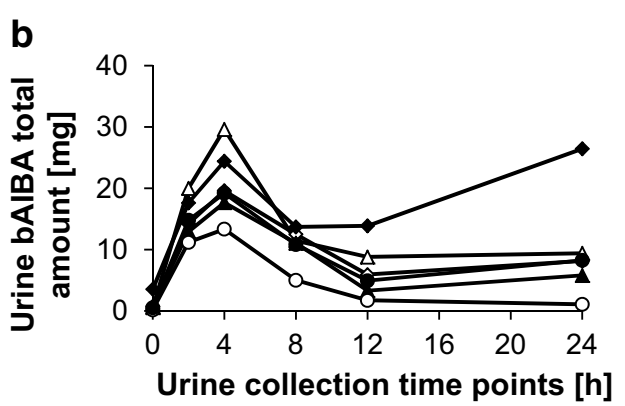

performance liquid chromatography-tandem mass spectrometry (UPLC-MS/MS) (b). It has to be noted that the values were calculated from the total amount of detected bAIBA and not from the difference from the baseline value, which resulted in an overestimation, including the endogenously formed bAIBA
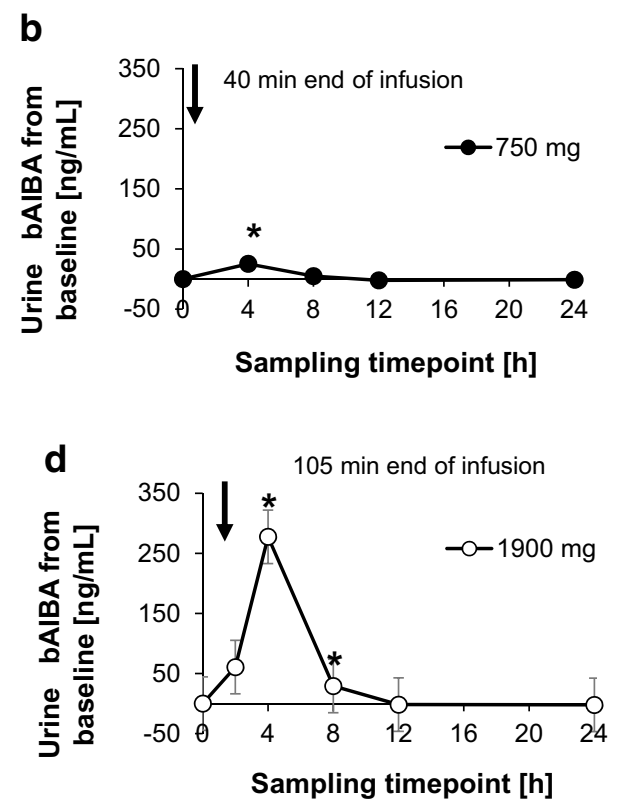

infusion or infusion only) (b), $1350 \mathrm{mg}$ (over $75 \mathrm{~min}$, infusion only) (c) and $1900 \mathrm{mg}$ (over $105 \mathrm{~min}$, infusion only) (d). Statistical significance was $\alpha=0.05-0.01\left(^{*}\right), \alpha=0.01-0.001$ (**), $\alpha \leq 0.001$ (***), 1 -sided paired Students $t$ test, the values at each time point were compared to the baseline (pre-dose) level

When looking at the bAIBA levels not only from the sole bAIBA perspective, but also including its relationship to the level of creatinine in urine $[\mathrm{mmol} \mathrm{bAIBA} / \mathrm{mol}$ creatinine], which is the basis on which this parameter is routinely assessed, at the highest dose of $1900 \mathrm{mg}$ the highest measured value of $458 \mathrm{mmol} / \mathrm{mol}$ creatinine (2-4 h after application) exceeded the normal upper value of $57.7 \mathrm{mmol} / \mathrm{mol}$ by about 8 times. At $8-12 \mathrm{~h}$ after application, the value fell back below its upper normal value ( $45 \mathrm{mmol} / \mathrm{mol}$ creatinine). The added-up amounts of bAIBA of the single collecting 


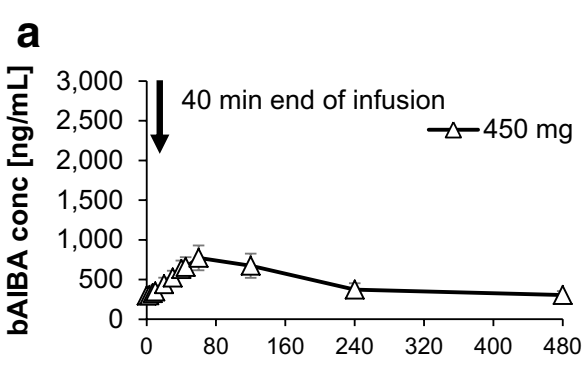

Sampling time-point [min]

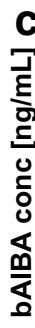

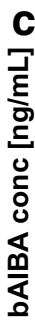

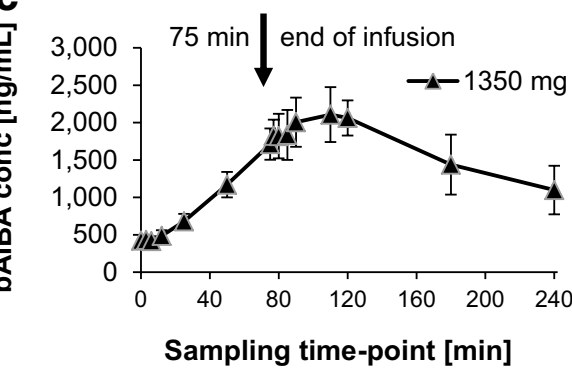

b

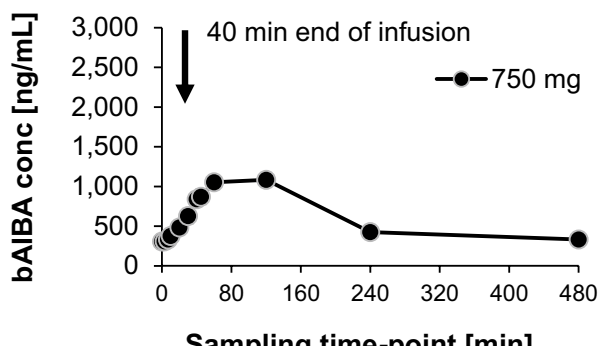

Sampling time-point [min]

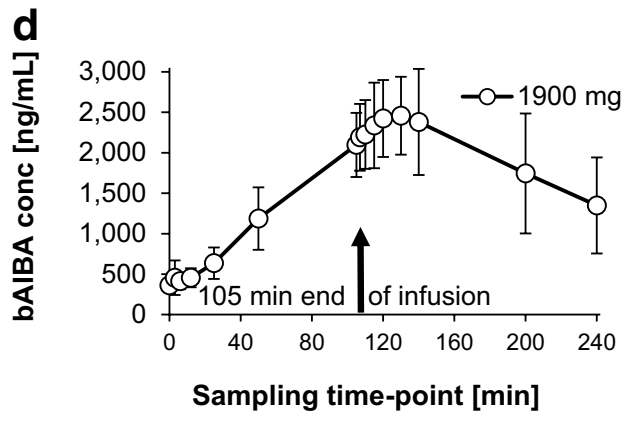

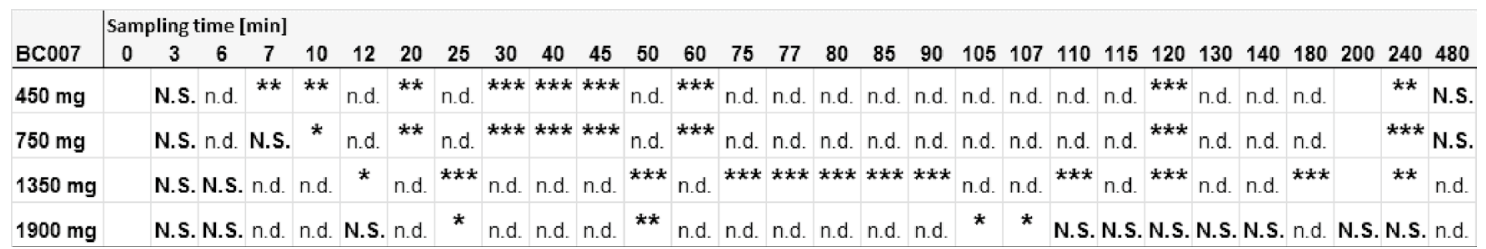

N.S. = not significant, n.d. $=$ not determind

Fig. 6 Beta-aminoisobutyric acid (bAIBA) plasma concentration in (ng/mL) measured via ultra-performance liquid chromatographytandem mass spectrometry (UPLC-MS/MS). Plasma samples collected at different time intervals as indicated in the figures. BC 007 dosing was $450 \mathrm{mg}$ (over $40 \mathrm{~min}$, bolus and infusion or infusion only) (a), $750 \mathrm{mg}$ (over $40 \mathrm{~min}$, bolus and infusion or infusion only)

intervals minus the pre-dose levels were set in relation to the maximal, possibly to find amounts of bAIBA of the single dosing groups. It revealed that $-1 \% \pm 18 \%$ and $5 \% \pm 6 \%$ were found at lower dosing cohorts of $450 \mathrm{mg}$ and $750 \mathrm{mg}$, respectively, while this percentage increased to $10 \% \pm 11 \%$ and $23 \% \pm 6 \%$, at the higher dosing cohorts of $1350 \mathrm{mg}$ and $1900 \mathrm{mg}$, respectively.

\section{4 bAIBA Determination in Plasma Samples Using UPLC-MS/MS}

bAIBA plasma concentration revealed a rapid increase starting at $3 \mathrm{~min}$ after the initial application (start of bolus/infusion) of BC 007 , which increased to its maximum shortly after the infusion ended and kept its maximum for about $20 \mathrm{~min}$ at $450 \mathrm{mg} \mathrm{BC} 007$ and $80 \mathrm{~min}$ at $750 \mathrm{mg}$ BC 007 , before being followed by a slow decline (b), $1350 \mathrm{mg}$ (over $75 \mathrm{~min}$, infusion only) (c), and $1900 \mathrm{mg}$ (over 105 min, infusion only) (d). Statistical significance of the data at single time-points compared to $0 \mathrm{~min}$ was $\alpha=0.05-0.01\left(^{*}\right), \alpha=0.01-$

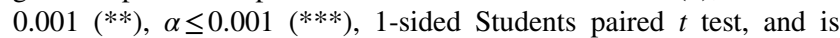
depicted in the table accompanying the figure

back to baseline levels (Fig. 6a, b). A similar but more pronounced kinetic was seen at doses of 1350 and $1900 \mathrm{mg}$ BC 007 (Fig. 6c, d). The ratio of the resulting concentration maxima of the formed bAIBA $(773 \pm 156 \mathrm{ng} / \mathrm{mL}$ to $1184 \pm 52 \mathrm{ng} / \mathrm{mL}$ to $2107 \pm 367 \mathrm{ng} / \mathrm{mL}$ ) was approximately equal to the ratios of the employed concentrations of $\mathrm{BC} 007$ (450 to 750 to $1350 \mathrm{mg}$, respectively) up to the concentration of $1350 \mathrm{mg}$. Concentration maxima ratios expressed in numbers are 1:1.53:2.73 compared to dose ratios of $1: 1.67: 3$. Beginning with a dose of $1350 \mathrm{mg}$, saturation of the decomposing enzymes was reached. The higher dose of $1900 \mathrm{mg}$ had a dose ratio of 4.2 compared to the $450 \mathrm{mg}$ dose (1:4.2), while the concentration maximum of bAIBA remained at $2458 \pm 482 \mathrm{ng} / \mathrm{mL}(130 \mathrm{~min})$ which corresponded to a ratio of $1: 3.18$ compared to the $450 \mathrm{mg}$ group and remained, therefore, closer to the one of its preceding dose of $750 \mathrm{mg}$. The corresponding 
Fig. 7 Baseline corrected uric acid (UA) serum concentration in samples collected at different time intervals as indicated in the figure. Dosing was $450 \mathrm{mg}$ (over $40 \mathrm{~min}$, bolus and infusion or infusion only) (a), $750 \mathrm{mg}$ (over $40 \mathrm{~min}$, bolus and infusion or infusion only) (b), $1350 \mathrm{mg}$ (over $75 \mathrm{~min}$, infusion only) (c), and $1900 \mathrm{mg}$ (over $105 \mathrm{~min}$, infusion only) (d) and an overview over all dosing regimes as well as including a follow-up check-up at $168 \mathrm{~h}$ after application (e). Statistical significance of the data at single time-points compared to 0 min was $\alpha=0.05-0.01(*)$, $\alpha=0.01-0.001{ }^{(* *)}, \alpha \leq 0.001$ (***), 1-sided Students paired $t$ test. At the dose of $750 \mathrm{mg}$ BC 007, significance occurred only if one value at $0 \mathrm{~min}$ (predose), exceeding the normal range, was taken out
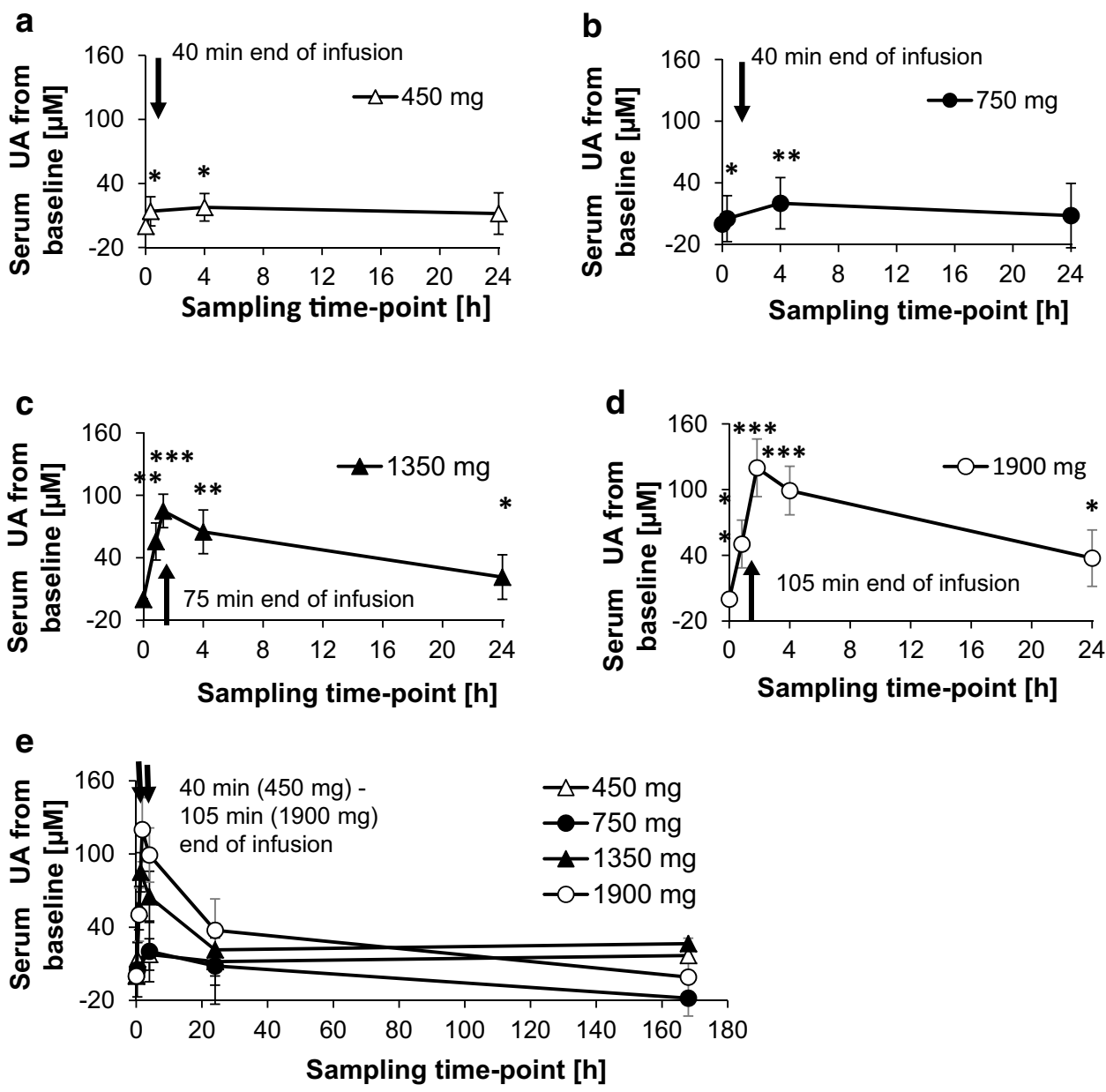

baseline (pre-dose) levels for the different dosing cohorts amounted to $297 \pm 67 \mathrm{ng} / \mathrm{mL}$ ( $450 \mathrm{mg}$ cohort), $308 \pm 33 \mathrm{ng} /$ $\mathrm{mL}$ (750 mg cohort), $423 \pm 65 \mathrm{ng} / \mathrm{mL}$ (1350 mg cohort), and $361 \pm 92 \mathrm{ng} / \mathrm{mL}$ (1900 mg cohort). The dose-corresponding BC 007 infusion rates were 7.5 and $11.25 \mathrm{mg} / \mathrm{min}$ (450 $\mathrm{mg}$ with or without bolus), 15.0 and $18.75 \mathrm{mg} / \mathrm{min}$ (750 mg with or without bolus), and $18 \mathrm{mg} / \mathrm{min}(1350 \mathrm{mg}$ and $1900 \mathrm{mg}$ without bolus).

In general, up to a dose of $750 \mathrm{mg} \mathrm{BC} \mathrm{007,} \mathrm{all} \mathrm{of} \mathrm{the}$ bAIBA plasma concentrations were below or around the reported normal upper value of $1031 \mathrm{ng} / \mathrm{mL}(10 \mu \mathrm{M}$ [4]). The highest measured single value of $3042 \mathrm{ng} / \mathrm{mL}(29.5 \mu \mathrm{mol} / \mathrm{L})$ at the dose of $1900 \mathrm{mg} \mathrm{BC} 007$ (at 115-140 min) exceeded this range by a factor of 3 .

\subsection{Uric Acid Determination in Serum Samples Using a Colorimetric Assay}

Figure 7 shows the increase in uric acid from the corresponding pre-dose levels. It became obvious that a significant increase in the level of uric acid was measurable, starting at a dose of $450 \mathrm{mg} \mathrm{BC} 007$ (Fig. 7b).

Furthermore, similar to plasma bAIBA, a fast increase in uric acid was detected shortly after starting BC 007 application, which reached its maximum at approximately $4 \mathrm{~h}$ after the initial application, or at 1.33 and $1.83 \mathrm{~h}$ as seen with 1350 and $1900 \mathrm{mg} \mathrm{BC} \mathrm{007,} \mathrm{respec-}$ tively, since the earlier sampling time-points were only introduced here. With respect to the absolute values, the highest measured value of $484 \pm 76 \mu \mathrm{mol} / \mathrm{L}$ at approximately $1.83 \mathrm{~h}$ after the initial application at the highest dose of $1900 \mathrm{mg}$ BC 007 slightly exceeded the normal upper range of $357 \mu \mathrm{mol} / \mathrm{L}$ for females (18-99 years, range $154.7-357 \mu \mathrm{mol} / \mathrm{L})$ and $428 \mu \mathrm{mol} / \mathrm{L}$ for males (18-99 years, range $208-428 \mu \mathrm{mol} / \mathrm{L})$. However, in this cohort, the mean of the pre-dose uric acid concentration already amounted to $364 \pm 77 \mu \mathrm{mol} / \mathrm{L}$. Furthermore, at the last treatment sampling time-point $(24 \mathrm{~h})$ the absolute value was already down to its pre-dose level, showing $364 \pm 77 \mu \mathrm{mol} / \mathrm{L}$. 
Fig. 8 Uric acid (UA) urine concentration $(\mu \mathrm{M})$. Samples were collected at different time intervals as indicated in the figure. Dosing was $450 \mathrm{mg}$ (over $40 \mathrm{~min}$, bolus and infusion or infusion only) (a), $750 \mathrm{mg}$ (over $40 \mathrm{~min}$, bolus and infusion or infusion only) (b), $1350 \mathrm{mg}$ (over $75 \mathrm{~min}$, infusion only) (c), and $1900 \mathrm{mg}$ (over $105 \mathrm{~min}$, infusion only) (d). Statistical significance was $\alpha=0.05-0.01$ (*), $\alpha=0.01-0.001(* *)$, $\alpha \leq 0.001$ (***), 1-sided Students paired $t$ test, the values at each time point were compared to the baseline (pre-dose) level
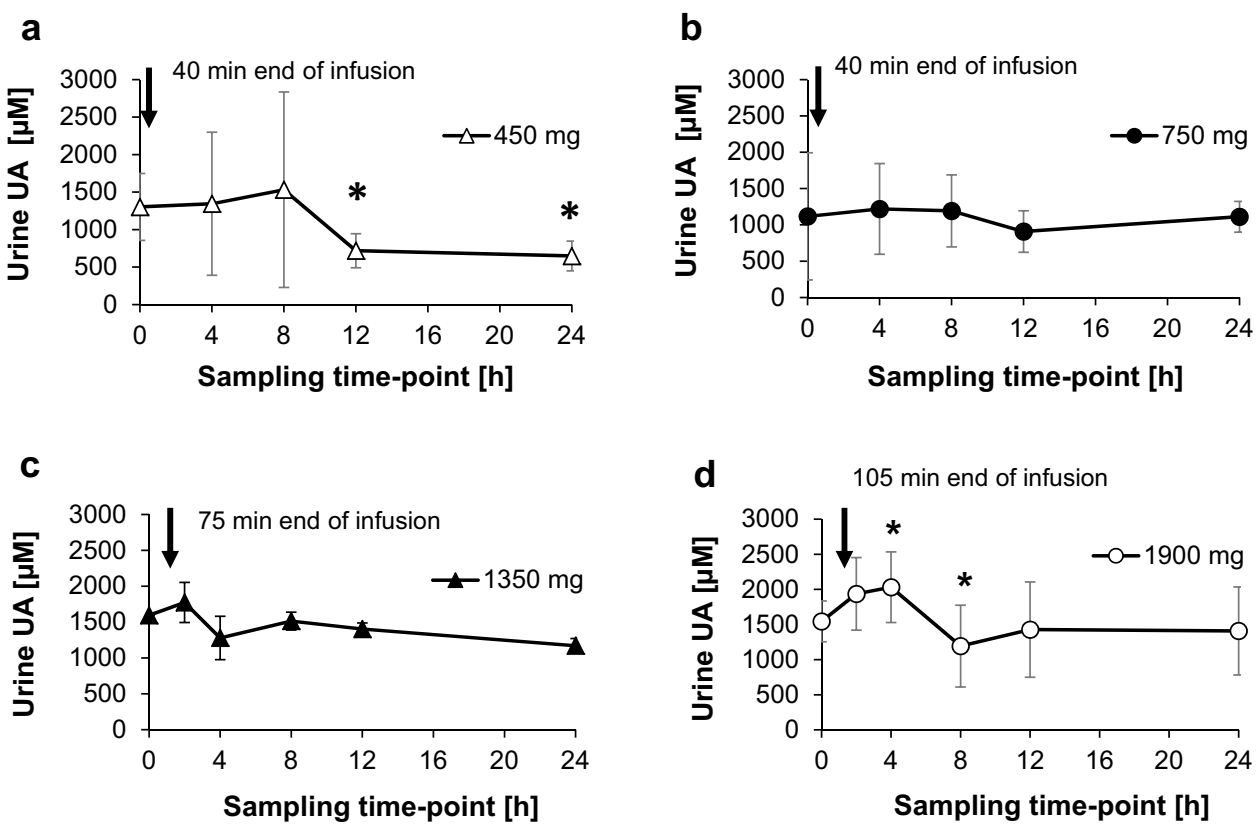

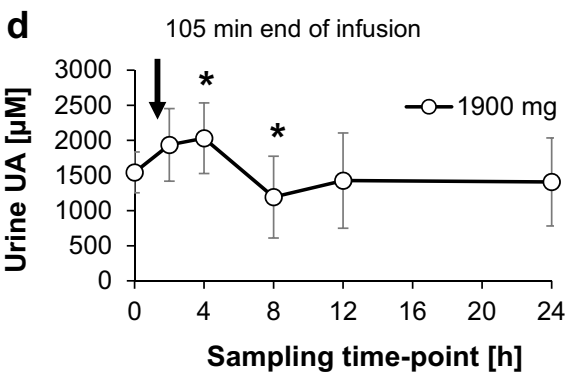

\subsection{Uric Acid Quantification in Urine Samples Using a Colorimetric Assay}

In urine, the uric acid concentration was measured using the 'ready to use' colorimetric kit as outlined in "Materials and methods".

The data revealed an early increase in urine uric acid; however, this was not significant because of the deviation within the single cohorts (Fig. 8).

In each case, the increased uric acid level returned to the corresponding pre-dose level at $8 \mathrm{~h}$ after BC 007 application or even slightly below, as in the case of the $450 \mathrm{mg}$ cohort (Fig. 8a).

With regard to the absolute amounts of the 24-h urine specimens, the highest amount of $615 \pm 78 \mathrm{mg} / 24 \mathrm{~h}$ at the highest dose of $1900 \mathrm{mg}$ BC 007 did not exceed the normal upper range of $1000 \mathrm{mg} / 24 \mathrm{~h}$.

\section{Discussion}

Compared to the efforts invested in the development of DNA therapeutics [5, 6], little has been reported about the exact metabolism and excretion when such DNA therapeutic agents are applied in humans. There are also few reports in the literature.

Some of the rare sources, especially of the non-modified small chain oligonucleotides, identified the kidneys as the main route of excretion, at least in animals, as shown by Ali et al. for the 21-mer EPI-2010 in rabbits [7]. A catabolism to nucleotides was also stated by the Oligonucleotide Safety Working Group (OSWG) in 2012 [8]. For a DNA-based drug, defibrotide, which is a polydisperse collection of the sodium salt of predominantly single-stranded oligodeoxyribonucleotides obtained from porcine intestinal mucosa and prepared by controled depolymerization of DNA [9], the Assessment report of the EMEA (EMEA/H/C/002393, 25 July 2013) stated the finding of the in vivo metabolism in rabbits assessed by plasma analysis following defibrotide administration by intravenous infusion for $2 \mathrm{~h}$, four times over a period of $24 \mathrm{~h}$ at $320 \mathrm{mg} / \mathrm{kg} / \mathrm{day}$. The in vivo study demonstrated the occurrence of nucleotides and nucleosides with free bases, resulting from the expected enzymatic degradation of the ssDNA. According to this assessment report, elimination in rats is mainly via urine and was very rapid, and the majority of the administered radioactive defibrotide was excreted by $24 \mathrm{~h}$ post-dosing [9]; together these stress the tendency of fast and complete in vivo degradation and excretion in animals.

Here, we reported investigations about the degradation and excretion of the 15-mer DNA product BC 007 in human plasma and urine. Even though the original intention was to detect degradation products of $n-1$ to $n-4$ of $\mathrm{BC} 007$ in the urine of treated subjects, according to the in vitro and ex vivo findings of Shaw et al. [2], bAIBA was also anticipated to be suitable to follow the fate of BC 007 in humans. bAIBA is a degradation product not only of valine (S-enantiomer) [10], but also of thymidine (R-enantiomer) in particular [11, 12]. Moreover, Truhaut et al. [11] and Mazurik et al. [12] have already published studies investigating urinary $\beta$-amino 
isobutyric acid in the mouse, elimination after intravenous administration of DNA, and the excretion of thymidine and beta-aminoisobutyric acid (bAIBA) in rats as a function of the administered dose of thymidine and DNA as early as 1965 and 1968, respectively. The $n-x$ degradation products of $\mathrm{BC} 007$ were, however, not detected in urine which was due to the combination of low specimen concentration and limit of quantification using the NMR hybridization method. Nevertheless, the further downstream degradation product, bAIBA, was detectable. The fast increase in the bAIBA concentration seen in urine was also confirmed when looking at its serum levels. Together these both stress the very fast and very complete decay of BC 007 in humans. This also explains why no $n-x$ degradation products could be found.

bAIBA is, therefore, a perfect parameter to follow the degradation of pyrimidine-containing nucleotide products in humans.

With respect to its physiological occurrence, it can be stated that in some laboratory manuals, bAIBA shows reference values in serum of up to $10 \mu \mathrm{M}$ throughout all age classes [4]. In urine, however, bAIBA showed low reference levels [13], and is reported by some sources to almost be undetectable since it is further catabolized by R(-)-baminoisobutyrate aminotransferase (also named alanineglyoxylate aminotransferase 2 (AGXT2)) to methylmalonic acid semialdehyde and propionyl-CoA.

Interestingly, about 2-20\% of Caucasians and up to $50 \%$ of the Asian population are reported to have a deficiency in this aminotansferase $[14,15]$, which results in an increased bAIBA level in urine without any pathological effects. Increased bAIBA levels in urine have also been reported in pathological situations when large amounts of DNA are degraded, such as malignancies [15, 16], body irradiation [17], and short-term starvation [18].

A recent study by Kittel et al. [19], applying HPLC-MS/ MS analytics for bAIBA detection, determined normal mean values in plasma of about $0.98 \mu \mathrm{M}(0.79-1.22 \mu \mathrm{M})$ in AGXT2 wild-type subjects (the majority of their investigated pool) and values of up to $2.72 \mu \mathrm{M}$ (the highest value of a single case) in the minority of investigated subjects, being homozygous for a specific single nucleotide polymorphism of AGXT2 (SNP rs 37369). In urine, these authors reported a mean of $42.5 \mu \mathrm{M}(4.4 \mathrm{mg} / \mathrm{L})$ bAIBA, when re-calculating from their mean bAIBA value given as $[\mu \mathrm{mol} / \mathrm{g}$ creatinine] and the mean creatinine value. It increased up to means of $117 \mu \mathrm{M}(12.05 \mathrm{mg} / \mathrm{L}) \mathrm{bAIBA}$ and even $1243 \mu \mathrm{M}(128 \mathrm{mg} / \mathrm{L})$ bAIBA, when looking at the same, but rare, single nucleotide polymorphism. For comparison, all the pre-dose levels from this study taken together amounted to a value of $12.8 \pm 8.3 \mathrm{mg} / \mathrm{L}$.

Despite the differences found in the published physiological ranges of bAIBA (probably due to different measuring techniques), it becomes clear that the human body obviously shows a high margin for an increase in bAIBA without any pathological effects [20].

Looking at the differences in the amount of bAIBA found in urine between the single subjects of a cohort in this study, as exemplarily shown for the $1350 \mathrm{mg}$ cohort in Fig. $4 \mathrm{~b}$, it was thought that in subjects showing the lowest amounts a possible further catabolism into methylmalonic acid semialdehyde and propionyl-CoA might have occurred [10]. However, no methylmalonic acid semialdehyde was detected, which may exclude a further breakdown within this 24-h observation time frame; however, final conclusions based on this metabolite should not be drawn. Furthermore, the racemization of (R)-methylmalonic semialdehyde via conversion to its ( $\mathrm{S}$ ) enantiomer was outlined by Roberts et al. [21], altogether making quantification extremely complicated. On the other hand, propionyl-CoA occurrence, as a second further breakdown product of bAIBA, has multiple origins that exclude its exploitation for the clarification of BC 007 metabolism.

Quantification of the metabolites, as a kind of recovery analysis of the applied amount of drug, becomes even more complicated, since at almost all stages of DNA degradation, the metabolites are also starting substances or building blocks, as in the case of nucleotides, starting the DNA synthesis salvation pathway [22]. Furthermore, besides the recycling of nucleotides, further downstream metabolites are also recycled, delivering components, for example, for the energy household (GTP) or second messengers such as cGMP. This is all common knowledge and already an obligatory part of educational text books about the topic [23]. Just by using this non-modified ssDNA, BC 007 might also serve as a valuable raw material in salvage pathways. Only the excess of immediately re-useable components will be excreted. This is reflected in the parallel increase of bAIBA recovery in urine with increasing applied doses, and has been previously investigated and reported [11]. This will explain while Reyderman and Stavchansky [24] observed a relatively long elimination half-life in some organs while investigating the pharmacokinetics and biodistribution of a nucleotide-based thrombin inhibitor in rats, using a radioactively labeled sequence.

In our in vivo study in humans, full-length $\mathrm{BC} 007$ in urine was almost negligible and BC $007 n-1$ to $n-4$ were not detectable. Whether the obviously not easily detectable intermediate break-down products are the reason, why there is hardly any literature on the metabolism of oligonucleotide drugs in humans, is pure speculation. The analytics of bAIBA and uric acid are perfectly able to circumvent any shortage in this respect; bAIBA might serve as the perfect biomarker, able to follow the fate of thymidine-containing DNA therapeutics in humans.

This metabolite could show that the conclusion drawn by Shaw et al. [2] from their plasma/serum in vitro-limited 
metabolism data that in vivo plasma metabolism plays a minor role in the overall in vivo elimination must be reviewed critically. In-vivo, metabolism is fast and more complete in humans, down to final degradation products and contributes to the overall elimination, which showed a half-life of about $4 \mathrm{~min}$ at the lower doses up to $750 \mathrm{mg}$ $\mathrm{BC} 007$ [1].

\section{Conclusions}

The 15-mer ssDNA drug, BC 007, was rapidly catabolized into the semi-final and final degradation products of its nucleic bases thymidine and guanosine, bAIBA and uric acid, respectively, which were detectable in blood and urine.

The estimation of bAIBA, especially in urine, is a valuable parameter to follow the metabolism and excretion of the drug, which should also hold true for other thymidinecontaining DNA-based drugs. Increased bAIBA levels do not bear any pathological consequences as already seen by physiologically increased levels and the excellent result of the safety and tolerability assessment of BC 007 (phase I) [1].

bAIBA levels declined back to the pre-dose level at 8-12 $\mathrm{h}$ after application. Measurement of uric acid in serum confirmed the fast degradation of BC 007 . The levels of uric acid in urine and in serum that were reached after application of $1300 \mathrm{mg}$ or even $1900 \mathrm{mg}$ BC 007 never or only slightly exceeded physiological concentrations, respectively.

Knowledge of the metabolism of DNA therapeutics is an encouraging prerequisite for exploiting the potential of these drugs in the treatment of various diseases.

Acknowledgements The manuscript was proofread by Proof-ReadingService (PRS).

Data availability All data generated or analysed during this study are included in this published article.

\section{Compliance with Ethical Standards}

Funding Part of this work was supported by a grant of AiF support GmbH, ZIM (grant no. ZF4447101AJ7).

Conflict of interest Hanna Davideit, Susanne Becker, Johannes Müller, Niels-Peter Becker, Peter Göttel, Ayşe Abay, and Annekathrin Haberland are employed by Berlin Cures. Johannes Müller, Peter Göttel, and Annekathrin Haberland are shareholders of the Berlin Cures Holding AG, the parent company of the Berliner branch Berlin Cures $\mathrm{GmbH}$. These authors have no other relevant affiliations or financial involvement with any organisation or entity with a financial interest in or financial conflict with the subject or materials discussed in the manuscript apart from those which are disclosed. Angela Sinn, Matthias Grossmann, Markus Mallek, and Hardy Weisshoff have no conflict of interest.
Ethical standards All procedures in this study were in accordance with the 1964 Helsinki declaration (and its amendments). EudraCTno. 2015-005236-18 (ethics committee approval).

Informed consent All subjects signed an informed consent form.

OpenAccess This article is distributed under the terms of the Creative Commons Attribution-NonCommercial 4.0 International License (http://creativecommons.org/licenses/by-nc/4.0/), which permits any noncommercial use, distribution, and reproduction in any medium, provided you give appropriate credit to the original author(s) and the source, provide a link to the Creative Commons license, and indicate if changes were made.

\section{References}

1. Mueller J, Haberland A, Becker N-P, Wenzel K, Wallukat G, Goettel P, et al. The DNA-based therapeutic agent bc 007 completely neutralizes agonistic autoantibodies directed against $\beta 1$-adrenoceptors: results of a phase 1 trial. J Am Coll Cardiol. 2018;71:A645.

2. Shaw JP, Fishback JA, Cundy KC, Lee WA. A novel oligodeoxynucleotide inhibitor of thrombin I In vitro metabolic stability in plasma and serum. Pharm Res. 1995;12:1937-42.

3. Hwang TL, Shaka AJ. Water suppression that works. Excitation sculpting using arbitrary wave-forms and pulsed-field gradients [Internet]. J Mag Reson. Ser. A. 1995. https://ac.els-cdn. com/S1064185885710479/1-s2.0-S1064185885710479-main. pdf?_tid=spdf-8173958a-b5a5-4ca1-b01e-31a2506cc3a0\&acdna $\mathrm{t}=1519745841$ Of53ed3785ccd92c18e9cff873485a52. Accessed 27 Feb 2018.

4. Laborlexikon: altersabhängige Normwerte für Aminosäuren im Serum 》 Facharztwissen für alle! 《 [Internet]. [cited 2018 Mar 29]. http://www.laborlexikon.de/Lexikon/Tabellen/03-Amino saeuren_im_Serum.htm.

5. Lundin KE, Gissberg O, Smith CIE. Oligonucleotide therapies: the past and the present. Hum Gene Ther. 2015;26:475-85.

6. Stein CA, Castanotto D. FDA-approved oligonucleotide therapies in 2017. Mol Ther J Am Soc Gene Ther. 2017;25:1069-75.

7. Ali S, Leonard SA, Kukoly CA, Metzger WJ, Wooles WR, McGinty JF, et al. Absorption, distribution, metabolism, and excretion of a respirable antisense oligonucleotide for asthma. Am J Respir Crit Care Med. 2001;163:989-93.

8. Schubert D, Levin AA, Kornbrust D, Berman CL, Cavagnaro J, Henry S, et al. The oligonucleotide safety working group (OSWG). Nucleic Acid Ther. 2012;22:211-2.

9. WC500153152.pdf [Internet]. http://www.ema.europa.eu/docs/ en_GB/document_library/EPAR___Public_assessment_report/ human/002393/WC500153152.pdf. Accessed 7 Feb 2018.

10. Podebrad F, Heil M, Beck T, Mosandl A, Sewell AC, Böhles H. Stereodifferentiation of 3-hydroxyisobutyric- and 3-aminoisobutyric acid in human urine by enantioselective multidimensional capillary gas chromatography-mass spectrometry. Clin Chim Acta Int J Clin Chem. 2000;292:93-105.

11. Truhaut R, Delacoux E, Paoletti C. Urinary beta-amino isobutyric acid in the mouse: elimination after intravenous administration of deoxyribonucleic acid. Nature. 1965;205:806-7.

12. Mazurik VK, Bryksina LE, Podgorodnichenko VK. A study of the excretion of thymidine and beta-aminoisobutyric acid (BAIBA) in rats as a function of the administered dose of thymidine and DNA. Radiobiologiia. 1968;8:17-22.

13. Nielsen HR. Variability in urinary-aminoisobutyric acid and creatinine in a human control group. Dan Med Bull. 1972;19:144-7. 
14. Evered DF, Barley JF. Infrequency of urinary excretion of betaaminoisobutyric acid by healthy humans. Clin Chim Acta Int J Clin Chem. 1978;84:339-46.

15. van Gennip AH, van Bree-Blom EJ, Abeling NG, van Erven AJ, Voûte PA. beta-Aminoisobutyric acid as a marker of thymine catabolism in malignancy. Clin Chim Acta Int J Clin Chem. 1987;165:365-77.

16. Abe M, Takahashi M, Nishidai T, Suyama S, Oshima S. The significance of urinary beta-aminoisobutyric acid in cancer patients. Int J Radiat Biol Relat Stud Phys Chem Med. 1973;24:73-9.

17. Smith H, Bates TH, Smith CI. Excretion of beta-amino-isobutyric acid as an index of radiation exposure. Int J Radiat Biol Relat Stud Phys Chem Med. 1964;8:263-9.

18. Sandler M, Pare CM. Starvation amino-aciduria. Lancet. 1954;266:494-5.

19. Kittel A, Müller F, König J, Mieth M, Sticht H, Zolk O, et al. Alanine-glyoxylate aminotransferase 2 (AGXT2) polymorphisms have considerable impact on methylarginine and $\beta$-aminoisobutyrate metabolism in healthy volunteers. PLoS One. 2014;9:e88544.

20. OMIM Entry-\# 210100—beta-aminoisobutyric aciduria; BAIBA [Internet]. https://www.omim.org/entry/210100. Accessed 12 July 2018.

21. Roberts LD, Boström P, O'Sullivan JF, Schinzel RT, Lewis GD, Dejam A, et al. $\beta$-Aminoisobutyric acid induces browning of white fat and hepatic $\beta$-oxidation and is inversely correlated with cardiometabolic risk factors. Cell Metab. 2014;19:96-108.

22. Fasullo M, Endres L. Nucleotide salvage deficiencies, DNA damage and neurodegeneration. Int J Mol Sci. 2015;16:9431-49.

23. Nucleotide: Abbau und Wiederverwertung [Internet]. Medici. https://viamedici.thieme.de/lernmodule/biochemie/nucleotide +abbau+und+wiederverwertung. Accessed 18 Apr 2018.

24. Reyderman L, Stavchansky S. Pharmacokinetics and biodistribution of a nucleotide-based thrombin inhibitor in rats. Pharm Res. 1998;15:904-10. 